\title{
Opinião sobre o Trânsito por Profissionais de Saúde
}

\author{
Knowledge of Traffic Humanization by Health Professionals
}

Opinión sobre El Trafico por Profesionales de la Salud

Luane Lira ${ }^{1}$

Adolfo Régis Feitosa Gomes ${ }^{2}$

Maria Stella Jakeline Alves De Farias ${ }^{3}$

Mayara Nakiria Tavares Da Rocha ${ }^{4}$

Marina Saldanha Rodrigues ${ }^{5}$

Maria das Graças Monte Mello Taveira ${ }^{6}$

\section{Resumo}

Objetivo: Levantar o conhecimento de profissionais de saúde sobre humanização no trânsito. Método: Estudo descritivo transversal realizado durante encontro nacional com 200 profissionais de saúde. Os dados foram analisados pelo programa EpiInfo 3.3.2. Resultados: $67,5 \%$ dos entrevistados eram do sexo feminino e $70,5 \%$ completaram o Ensino Superior, estando a maioria da amostra acima dos 40 anos, com $44,1 \%$ atuando como gerentes ou diretores da saúde. Cerca de $40 \%$ dos participantes do congresso afirmaram ter sofrido algum tipo de acidente de trânsito, destes, $65 \%$ foram causados por mulheres e $73,1 \%$ por pessoas de Ensino Superior Completo. Quando questionados sobre a responsabilidade e prioridade no trânsito encontrou-se que $92,5 \%$ dos pesquisados afirmaram que os pedestres são os principais responsáveis pelo trânsito. Conclusão: $\mathrm{O}$ profissional da saúde deve conhecer as responsabilidades no trânsito e promover a humanização nesse contexto, construindo valores para a melhoria da qualidade de vida e assim contribuir para a diminuição da

${ }^{1}$ Médico clínica Universidade Federal de Alagoas. *Autora correspondente: Campus A. C. Simões. Av. Lourival Melo Mota, s/n. Tabuleiro dos Martins. Maceió, Alagoas, Brasil. 57072-900. Email: luanelira@hotmail.com.

${ }^{2,3,4}$ Médico(a) Clínico(a) Geral pela Universidade Federal de Alagoas

${ }^{5}$ Graduanda em Medicina pela Universidade Federal de Alagoas.

${ }^{6}$ Doutoranda do Programa de Ciências da Saúde do ICBS/UFAL. Profa. Ms. FAMED/UFAL 
morbimortalidade decorrente dos acidentes de trânsito.

\section{Descritores: Humanização; Trânsito;}

Saúde.

Abstract

Objective: To raise the knowledge of health professionals about humanization in traffic. Methods: A cross-sectional descriptive study carried out during a national health meeting with 200 Health Professionals. Data were analyzed by Epi Info program version 3.3.2. Results: $67.5 \%$ of the interviewees were female and $70.5 \%$ went to the University, with the majority of the sample over 40 years old, and $44.1 \%$ acting as managers or directors in Health Institutions. About $40 \%$ of the participants reported that they have suffered some kind of traffic accident; related to this number, $65 \%$ was cited by women and $73.1 \%$ by people who finished graduation. When questioned about the responsibility and priority in traffic, it was found that $92.5 \%$ of the interviewees stated that pedestrians are the main responsible for traffic. Conclusion: there has been noticed a delegation of responsibility to pedestrians in traffic dynamics, which norms and laws do not establish; this shows the need of greater knowledge on this subject for health professionals.

\section{Descriptors: Humanization; Traffic;}

Health.

\section{Resumen}

Objetivo: Evaluar los conocimientos de profesionales de salud cerca de la humanización en el tráfico. Metodología: Estudio descriptivo transversal echo durante una reunión nacional sobre la salud, con 200 profesionales de la salud. Se analizaron los datos según el programa EpiInfo 3.3.2. Resultados: $67,5 \%$ de los encuestados eran mujeres y el 70,5\% había completado los estudios universitarios, con la mayoría de la muestra por encima de 40 años, con un $44,1 \%$ trabajando como gerentes o directores de salud. Alrededor del $40 \%$ de los encuestados reportaron haber experimentado algún tipo de accidente de tráfico; de éstos, $65 \%$ fueron citados por las mujeres y $73,1 \%$ por personas que tenían estudios universitarios completos. Cuando se le preguntó acerca de la responsabilidad $y$ prioridad en el tráfico, se encontró que el 92,5\% de los encuestados dijo que los 
peatones son los principales responsables del tráfico. Conclusión: Se ha producido una delegación de la responsabilidad a los peatones en la dinámica de tráfico, que no está establecida por las normas y leyes; esto muestra la necesidad de un mayor conocimiento sobre este tema por los profesionales en salud.

\section{Descriptores: Humanización; Tráfico;}

\section{Salud.}

\section{Introdução}

Historicamente, o trânsito sempre foi tratado como questão policial e de comportamento individual dos usuários, carecendo de um tratamento no campo da engenharia, da administração do comportamento e da participação social $^{(1)}$. Os últimos 60 anos levaram ao processo de urbanização, que se intensificou ao redor do mundo, especialmente nos países subdesenvolvidos industrializados, como o Brasil, trazendo a necessidade da reorganização da ideia e do próprio trânsito, devido, principalmente, ao número crescente de veículos na frota ${ }^{(2)}$.

A mobilidade do cidadão no espaço social, centrada nas pessoas que transitam e não na maneira como transitam, é ponto principal ao considerar a liberdade de ir e vir, de atingir-se o destino que se deseja, de satisfazer as necessidades de trabalho, de lazer, de saúde, de educação e outras. Assim, sob o ponto de vista do cidadão que busca melhor qualidade de vida, o trânsito toma nova dimensão ao promover o bem-estar social ao unir-se a ideia de fluidez e eficácia ${ }^{(1)}$.

Observando sob a ótica da violência e segurança no trânsito, estima-se que, a cada ano, morrem milhões de pessoas vítimas de acidentes de trânsito ao redor do mundo, sendo que os acidentes são previstos como o terceiro maior contribuinte para os agravos à saúde no mundo em $2020^{(3)}$. A maior parte do aumento previsto desses acidentes irá ocorrer em regiões de baixa e média renda, devido não só ao rápido crescimento no número de veículos motorizados, mas também à exposição aos fatores de risco, tais como a velocidade e o álcool, agravada por execução inadequada das regras de trânsito ${ }^{(4)}$. Além do grande número de óbitos, eles são também responsáveis por 50 milhões de pessoas feridas ou incapacitadas $^{(5)}$.

No Brasil, os acidentes de trânsito assumem uma representação altamente significativa das taxas de 
morbimortalidade, chegando a $50 \%$ em alguns municípios. A frota de veículos atual do Brasil está estimada em 66.116.077 veículos. Nos anos anteriores a 2001, essa frota era de 30.267.649 veículos. Isso mostra um crescimento de mais de $50 \%$ em apenas 10 anos. O Brasil mata, por ano, cerca de trinta e sete mil pessoas e provoca a internação de outras $180 \mathrm{mil}$, com um impacto de aproximadamente 34 bilhões de reais ${ }^{(6)}$.

A crescente quantidade e gravidade destes números é uma das facetas do trânsito que exige minimização por parte dos cidadãos e seus órgãos reguladores. Muitos problemas que são comuns às grandes e médias cidades se juntam aos acidentes: domínio quase absoluto dos automóveis no tráfego, espaço restrito para mobilidade dos pedestres, uso desordenado das vias públicas pelos seus usuários, sejam motoristas, motociclistas, ciclistas, carroceiros e pedestres. A realidade atual necessita de educação preventiva no trânsito por parte dos cidadãos com intensa e eficaz regulamentação pelo poder público através de normas de conduta no trânsito. A "humanização do trânsito" surge como uma aliada para sanar estes problemas.
Segundo a Política Nacional de Trânsito na Resolução 166, a participação da sociedade nas discussões dos problemas e das soluções é essencial para a consecução de um comportamento coletivo seguro, respeitoso e não agressivo no trânsito. Por exigir responsabilidade de toda sociedade civil, a educação e cidadania em torno destas questões perpassa por fatores históricos, sociais e culturais complexos que envolvem áreas como a saúde, segurança, educação e assistência social e que culminam em nãoresolutividade e o agravamento dos problemas no trânsito ${ }^{(1)}$.

A humanização no trânsito ultrapassa a isolada transmissão de informações ao focar no ser humano e trabalhar mudanças de valores, comportamentos e encorajar novos hábitos e atitudes por meio de uma nova percepção de realidade e adaptação do trânsito. Não se limita a eventos esporádicos, não permite ações descoordenadas e pressupõe um processo de aprendizagem continuada ${ }^{(1)}$.

A escassez de estudos nesta área denota a importância da pesquisa, que tem por objetivo levantar as informações, opiniões e o conhecimento de profissionais da área de saúde sobre humanização no trânsito, permitindo 
fazer um mapeamento analítico de seus problemas, características e consequências, e a partir daí, criar medidas intervencionistas para a sua prevenção $^{(8)}$.

\section{Método}

Trata-se de um estudo descritivo transversal realizado durante encontro nacional de saúde em Maceió, Alagoas, em 2012, com 200 profissionais de diversos âmbitos da área da saúde, trabalhadores do Ministério da Saúde ou não, e que consentiram participar do estudo.

$\mathrm{O}$ instrumento utilizado foi um questionário elaborado pelos pesquisadores, embasado na literatura composto por questões objetivas e subjetivas relacionadas com as opiniões e condutas tomadas no trânsito e caracterização socioeconômica.

A coleta de dados foi efetuada por estudantes do curso universitário de medicina. Inicialmente eram contatados os coordenadores da apresentação que explicava a todos os congressistas $\mathrm{o}$ objetivo da pesquisa, e aqueles que concordavam em participar recebiam o instrumento e o TCLE com as devidas explicações.

Após coletados dados, seguiu-se a digitação e análise no programa Epi Info, versão 3.3.2.

Apresenta-se neste momento o perfil socioeconômico dos congressistas, o uso e a frequência dos meios de transporte, envolvimento em acidentes de trânsito e caracterização do trânsito da cidade onde reside. A pesquisa foi aprovada pelo Comitê de Ética e Pesquisa da Universidade Federal de Alagoas processo $\mathrm{n}^{\circ}$ 11467912.3.0000.5013.

\section{Resultados}

A amostra foi composta por 200 participantes da área da saúde, sendo $67,5 \%$ do sexo feminino e $70,5 \%$ que completaram o Ensino Superior. As faixas de idade predominantes estavam entre 50 e 59 anos $(31,8 \%)$ e entre 40 49 anos $(30,3 \%)$, o que mostra que a maioria da amostra estava acima dos 40 anos de idade, $44,1 \%$ deles atuavam como gerentes ou diretores da saúde e $18,7 \%$ denominaram-se coordenadores (Tabela 1). 
Tabela 1 - Dados sócio demográficos dos participantes da pesquisa

\begin{tabular}{|c|c|}
\hline $\begin{array}{l}\text { Variável } \\
\text { Sexo }\end{array}$ & n (\%) \\
\hline Masculino & $65(32,5 \%)$ \\
\hline Feminino & $135(67,5 \%)$ \\
\hline Nível Educacional & \\
\hline Ens. Fund. Incompleto & $01(0,5 \%)$ \\
\hline Ens. Med. Completo & $10(5,0 \%)$ \\
\hline Ens. Sup. Incompleto & $19(9,5 \%)$ \\
\hline Ens. Sup. Completo & $141(70,5 \%)$ \\
\hline Mestrado & $26(13,0 \%)$ \\
\hline Doutorado & $03(1,5 \%)$ \\
\hline Idade (anos) & \\
\hline $18-29$ & $15(7,6 \%)$ \\
\hline $30-39$ & $44(22,2 \%)$ \\
\hline $40-49$ & $60(30,3 \%)$ \\
\hline $50-59$ & $63(31,8 \%)$ \\
\hline+60 & $16(8,1 \%)$ \\
\hline
\end{tabular}

O carro é o veículo mais utilizado pelos pesquisados e também é o tipo de veículo normalmente usado diariamente. Uma única exceção significativa é a única pessoa que afirma normalmente usar o trem como meio de transporte, sem utilizá-lo todos os dias. (Tabela 2).

Tabela 2 - Veículos utilizados pelos pesquisados

\begin{tabular}{llr}
\hline Veículo & $\mathrm{n}$ & $\%$ \\
\hline Bicicleta & 07 & $3,8 \%$ \\
Carro & 160 & $81,0 \%$ \\
Metrô & 05 & $2,5 \%$ \\
Moto & 05 & $2,5 \%$ \\
Ônibus & 20 & $10,1 \%$ \\
Trem & 01 & $0,7 \%$ \\
\hline
\end{tabular}

Cerca de $40 \%$ dos participantes da pesquisa afirmaram ter sofrido algum tipo de acidente de trânsito. Destes acidentes $11,5 \%$ foram com vítimas e apenas um destes pesquisados fazia uso da bicicleta, todo o restante usava carro.
Os veículos normalmente utilizados todos os dias por estes indivíduos estão distribuídos da seguinte forma: $81 \%$ são carros, $10,1 \%$, ônibus, 3,8\%, bicicleta e 2,5\%, motocicletas. Cerca de $65 \%$ dos acidentes que ocorreram foram citados 
por mulheres e $73,1 \%$ por pessoas com Ensino Superior Completo.

Quando questionou-se sobre a responsabilidade e prioridade no trânsito encontrou-se que $92,5 \%$ dos pesquisados afirmaram que os pedestres são os principais responsáveis pelo trânsito, seguidos pelas bicicletas e motos (Gráfico 1).

\section{Gráfico 1 - Opinião sobre a responsabilidade no trânsito (\%)}

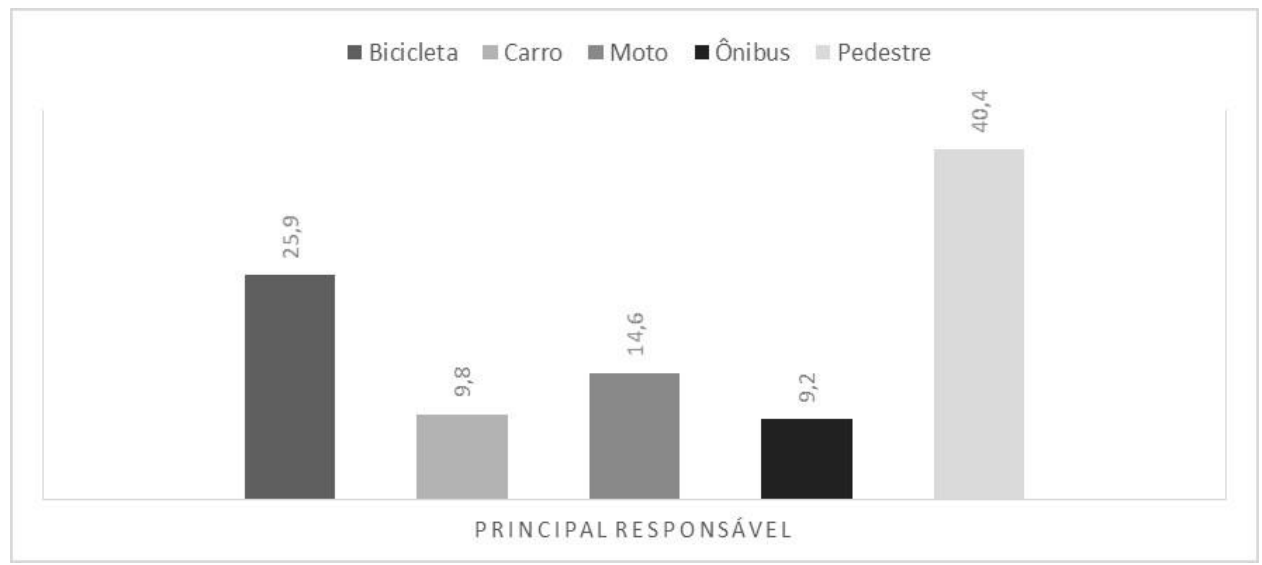

O trânsito da cidade de residência dos pesquisados é descrito por eles como ruim $(31,5 \%)$, desorganizado $(30,7 \%)$ e imprudente $(29,9 \%)$ (Gráfico 2). Outras afirmações foram apontadas: estressante, bom e caótico (como primeira palavra), diversificado, perigoso e organizado (como segunda) e conturbado, pesado e adequado (como terceira). É interessante notar que condutores e pedestres escolherem a característica "imprudente", o que leva a refletir sobre a quantidade de veículos, mas também da qualidade do trânsito.

\section{Gráfico 2 - Descrição do trânsito do local onde residem (\%)}

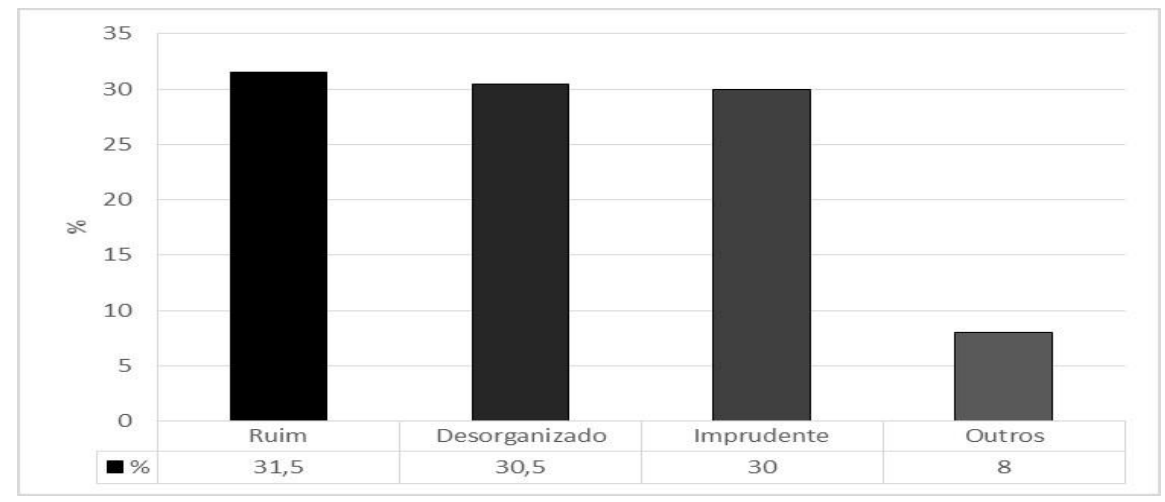




\section{Discussão}

Os dados obtidos são consonantes com a literatura geral e revelam diversas características do trânsito na opinião dos pesquisados. O uso predominante de veículos automotivos (carros) no país é confirmado, demonstrando o dado do rápido crescimento da frota brasileira nas últimas décadas, de 430.000 em 1950, para 3,1 milhões em 1970, chegando a 49,8 milhões em $2015^{(1,7-8)}$. Fato ocorrido com as transformações vividas no Brasil nas últimas décadas, com destaque ao desenvolvimento das indústrias automobilísticas e ao aumento de sua produção.

Todos esses avanços e mudanças tecnológicas fizeram com que o crescimento da cidade acontecesse de forma desordenada, sem infraestrutura adequada, pois os centros urbanos, em geral, não foram planejados para o crescimento da frota de veículos. Uma situação que pode estar relacionada é a qualidade insatisfatória dos transportes coletivos nas grandes cidades brasileiras, o que fez com que as pessoas optassem por meios de transportes individuais, o que piorou os problemas de trânsito nas grandes cidades $^{(10)}$.
As adaptações das cidades feitas para o constante uso de automóveis, levam à violação da natureza, com poluição do meio ambiente, em detrimento da qualidade de vida em áreas residenciais e de uso coletivo, como praças e áreas de lazer, cedendo espaços para abertura de novas vias, não planejadas. Assim, a fluidez do trânsito influencia no comportamento dos condutores de veículos automotivos e dos pedestres.

O transito é uma questão de saúde pública uma vez que acidentes por atropelamento por veículos acontecem em alta escala nos últimos anos no Brasil $^{(11)}$. Fato importante para o entendimento da ocorrência de lesões explicadas pelos tipos de acidente e de veículos envolvidos. No Brasil, 400.000 pessoas sofrem por ano algum tipo de ferimento decorrente de acidentes de trânsito ${ }^{(12)}$.

Os motociclistas também se destacam entre as principais vítimas de acidentes de trânsito, o que pode ser explicado através da crescente tendência de seu uso, uma vez que é um veículo ágil e de baixo custo, mas em contrapartida é menos seguro que um automóvel, o que torna o seu condutor um sujeito mais exposto ao risco de sofrer múltiplos traumas e lesões de 
maior gravidade ${ }^{(14)}$. Apesar dos achados desse estudo terem baixos índices de referência ao uso de motocicletas, o que pode ser explicado pelas características sociais dos participantes, além da maioria ser do sexo, uma vez que as pesquisas mostram que esse veículo tende a ser mais usado pelo sexo $\operatorname{masculino}^{(15)}$.

Os acidentes de trânsito segundo o Ministério da Saúde ${ }^{(16)}$ causam um impacto negativo na população brasileira, que além de ter a perda de anos de vida livres de incapacidade, da redução da expectativa de vida dos adolescentes e jovens, também acarreta altos custos sociais e econômicos impostos ao sistema de saúde e previdenciário, considerando-se que os acidentes de trânsito são uma das principais causas de mortes de jovens no país.

Percebe-se o distanciamento dos pesquisados sobre suas responsabilidades no trânsito, uma vez que eles apontaram os carros, que normalmente são utilizados todos os dias, como os menos responsáveis que os pedestres, bicicletas ou motos. O que coloca a máquina ou os eu condutor como prioridade frente o pedestre e o ser humano.
Para Hoffman ${ }^{(16)}$ o Brasil cultua o motorista do automóvel como o único cidadão de direitos no trânsito, ideia provinda de uma cultura voltada para o autoritarismo, no qual o automóvel é visto como símbolo de status e poder. Afirmando ele que, para o pedestre sobra uma posição submissa, sendo considerado com menor importância, o que reflete sua fragilidade diante do 'escudo de ferro' dos motoristas ${ }^{(16)}$.

A explicação para tal resultado pode ser respaldas nas chamadas representações idealizadas da tarefa de dirigir, que atribuem significados de responsabilidade e atenção a maneira como cada indivíduo se concebe como motorista $^{(17)}$. Assim, visualiza-se as diferenças nas representações e utilização do carro para as pessoas, ocorrendo muitas vezes a priorização da máquina sobre o homem.

Para a modificação de tal pensamento é essencial o exercício da Educação para o Trânsito como parte de uma educação ético-social para os cidadãos brasileiros, ocorrendo a integração do tema aos currículos em todos os níveis da educação brasileira, com a promoção do conhecimento e criação de prática, hábitos, atitudes e comportamentos coerentes com a demanda do trânsito atual ${ }^{(18)}$. 
Muitos motoristas usam seus carros como espaço de privacidade, dando-se o direito de ser conforme age em sua própria casa, o que contribui para o surgimento e agravamento de conflitos no trânsito provenientes dos diferentes padrões de comportamentos dos outros usuários do mesmo espaço público $^{(16)}$.

A maioria das definições para o trânsito de suas cidades pelos pesquisados foram: "ruim", “desorganizado" e “imprudente", e essas mesmas palavras podem também caracterizar as vias, os veículos e o comportamento do participante no trânsito. Este trânsito, por sua vez, é delimitado pelo conhecimento, pela prática e pelas atitudes de cada participante, levando a crer que todos os cidadãos são causa e consequência da sociedade $^{(16)}$.

Apesar de toda a eficiente normatização para a fluidez do tráfego, não há garantia do controle do conjunto dos comportamentos que compõe a atividade de dirigir automóveis ou caminhar como pedestre. Isto, comumente, leva à caraterização do trânsito como ruim, sinônimo de que a circulação nas vias não flui tranquilamente e resultado das próprias atitudes do homem ${ }^{(16)}$.
Tudo está relacionado a educação e humanização do comportamento das pessoas frente a este aspecto. Mostrando a importância de maiores discussões sobre o tema, a fim de que o ser humano seja valorizado bem como sua qualidade de vida.

\section{Conclusão}

O profissional da saúde não pode ficar indiferente ao processo de humanização do trânsito, devendo conhecer as suas responsabilidades enquanto participante quer como pedestre, passageiro ou condutor de um veículo, quer como profissional que irá atender as vítimas dos acidentes de trânsito, ou como gestor do serviço saúde. Pois sua principal função permeia o campo da promoção e educação em saúde, ou seja, o campo da (re)construção de valores e conhecimentos que vise a melhora da qualidade de vida da população.

Os prejuízos à qualidade de vida da sociedade, decorrente da má organização e violência, ocorridos no trânsito são vigentes e nesse contexto, a humanização surge como tácita solução, que gradativamente visa modificar os valores errados e as atitudes de risco (desrespeito às leis, alta velocidade, 
entre outros), mediante a educação e cidadania, com a finalidade de dirimir os altos índices de morbimortalidade decorrente dessas atitudes no trânsito, que terminam por gerar acidentes, cujo imenso ônus financeiro, cabe aos cofres públicos arcar.

\section{Referências}

1. Ministério das Cidades (BR). Política Nacional de Trânsito: Trânsito, questão de cidadania. Cadernos Mcidades Trânsito. Brasília: Ministério das Cidades; 2004.

2. Oliveira ZC, Mota ELA, Costa MCN. Evolução dos acidentes de trânsito em um grande centro urbano, 1991-2000. Cad. Saúde Pública. 2008; 24(2):36472.

3. World Health Organization. Road traffic injury prevention: an assessment of risk exposure and intervention costeffectiveness in different world regions. [online]. 2008 [cited 2011 Jul 15]. Available from: http://www.who.int/choice/publications/ d_2009_road_traffic.pdf.

4. Araujo MM, Malloy-Diniz LF, Rocha FL. Impulsividade e acidentes de trânsito. Rev. psiquiatr. clín. 2009; 36(9):60-8.

5. Cavalcante FG, Morita PA, Hadda SR. Sequelas invisíveis dos acidentes de trânsito: o transtorno de estresse póstraumático como problema de saúde pública. Ciênc. saúde coletiva. 2009; 14(5):1763-72.
6. Jorge MHPM, Latorre MRDO. Acidentes de trânsito no Brasil: dados e tendências. Cad. Saúde Pública. 2011; 27(8): 1654-8.

7. Departamento Nacional de Trânsito (BR). Frota de veículos, março 2011. [online]. 2011. [acesso em 2011 abr. 28]. Disponível em: http://www.denatra n.gov.br/frota.htm.

8. Departamento Nacional de Trânsito (BR). Frota de veículos, dezembro 2015. [online]. 2015. [acesso em 2016 out. 05]. Disponível em: http://www.denatran,gov.br/frota.htm 9. Marin L, Queiroz MS. A atualidade dos acidentes de trânsito na era da velocidade: uma visão geral. Cad. Saúde Pública. 2000; 16(2):7-21.

10. Anjos KC, Evangelista MRB, Silva JS, Zumiotti AV. Paciente vítima de violência no trânsito: análise do perfil socioeconômico, características do acidente e intervenção do Serviço Social na emergência. Acta ortop. bras. 2007; 15(5):262-6.

11. Ministério das Cidades (BR). Confederação Nacional de Municípios. Mapeamento das mortes por acidentes no Brasil. Brasília: Ministério das Cidades (BR); 2009.

12. Abreu AMM, Lima JMB, Matos LN, Pillon SC. Uso de álcool em vítimas de acidentes de trânsito: estudo do nível de alcoolemia. Rev. LatinoAm. Enfermagem. 2010; 18: 513-20.

13. Soares DFPP, Mathias TAF, Silva DW, Andrade SM. Motociclistas de entrega: algumas características dos acidentes de trânsito na região sul do Brasil. Rev. bras. epidemiol. 2011; 14(3):435-44. 
14. Ministério da Saúde (BR). Secretaria de Vigilância em Saúde. Vigilância de Violências e Acidentes em Serviços Sentinelas - VIVA. Brasília: Ministério da Saúde (BR); 2006.

15. Ministério da Saúde (BR). Departamento de Análise de Situação em Saúde, Secretaria de Vigilância em Saúde. Saúde Brasil 2006: uma análise da situação de saúde. Brasília: Ministério da Saúde (BR); 2006.

16. Hoffman MH, Cruz RM, Alchieri JC. Comportamentos no trânsito. $2^{\mathrm{a}}$ ed. São Paulo: Casa do Psicólogo, 2003.

17. Lagares RB. A representação social do trânsito como prática social complexa. Goiânia. Dissertação [Mestrado] - Universidade Católica de Goiás. 2001.

18. Silva FB. Dirigindo seu Automóvel sem Medo: Programa de Habilitação para o Trânsito. Campinas: Copola, 1998. 